\title{
Vulnerability to Tardive Dyskinesia Development in Schizophrenia: An FDG-PET Study of Cerebral Metabolism
}

Sally Szymanski, D.O., Ruben C. Gur, Ph.D., Fiona Gallacher, M.S., Lyn Harper Mozley, Ph.D., and Raquel E. Gur, M.D., Ph.D.

An understanding of the development of tardive dyskinesia (TD) may require prospective studies assessing the relationship of brain function measures to behavior. This study was undertaken to determine whether predisposition to the development of $T D$ is related to abnormalities of cerebral ${ }^{18}$ F-labeled 2-fluoro-2-deoxy-D-glucose (FDG) positron emission tomography (PET) measures in schizophrenia. A group of 42 patients without TD underwent FDG PET scanning for measuring cerebral metabolism as well as neuropsychological evaluation and magnetic resonance imaging. Patients were assessed longitudinally for TD development. Eight patients developed TD within 3 years. They were matched to eight patients without TD. Glucose metabolic rates and region/

KEY WORDS: Tardive dyskinesia; Neuroimaging; Schizophrenia

Tardive dyskinesia (TD) is a disabling condition without reliably effective treatment. Clinical risk factors for TD include aging with a higher incidence among older patients, the presence of bipolar disorder, "organic"

From the Mental Health Clinical Research Center, Neuropsychiatry Section, Department of Psychiatry, University of Pennsylvania School of Medicine, Philadelphia, PA. Dr. Szymanski is now at the Division of Nuclear Medicine and Radiation Health Sciences, Johns Hopkins University and Ms. Gallacher is now at the Department of Psychology, Michigan State University.

Address correspondence to: S. Szymanski, D.O., Division of Nuclear Medicine and Radiation Health Sciences, Johns Hopkins Medical Institutions, JHOC Research-Room 3245, 601 N. Caroline Street, Baltimore, MD 21287-0807. Please send a copy of the correspondence to: R.E. Gur, M.D., Ph.D., Director, Neuropsychiatry Section, Department of Psychiatry, Hospital of the University of Pennsylvania, 10th Floor Gates Building, Philadelphia, PA 19104.

Received March 10, 1995; accepted April 23, 1996 whole brain ratios were examined in 38 regions of interest per hemisphere. Whole brain metabolism did not differ between the two groups. However, relative hypermetabolism in temporolimbic, brainstem, and cerebellar regions and hypoactivity in parietal and cingulate gyrus were found in the patients who later developed TD in contrast to those who did not. The groups were matched on clinical measures and had similar neuropsychological and neuroanatomic testing results. Thus, differences in the metabolic activity of specific brain regions are associated with vulnerability to TD development. (c) 1996 American College of Neuropsychopharmacology [Neuropsychopharmacology 15:567-575, 1996]

brain disorders, diabetes mellitus, metaclopramide use, early occurring extrapyramidal side effects secondary to antipsychotic medication initiation and cumulative neuroleptic dosage (Casey 1993).

To identify biologic correlates of this disorder, attempts have been made to relate brain abnormalities on neuroimaging and neuropsychology studies to the presence of TD. Those investigations include: neuroimaging studies of TD that have examined receptor density and binding affinity with positron emission tomography with negative results (Blin et al. 1989; Andersson et al. 1990); and limited conflicting research regarding neuroanatomic measures with computed tomography (CT) (Albus et al. 1985; Gold et al. 1991; Hoffman and Casey 1991; Dalgalarrondo and Gattaz 1994) and magnetic resonance imaging (MRI) (Heinz et al. 1988; Mion et al. 1991; Elkashef et al. 1994). Waddington et al. (1987, 1993) have studied neurocognitive change in schizo- 
phrenic subjects with TD and have reported an association between cognitive dysfunction and TD. The positive findings in a portion of the CT, MRI, and psychological literature in patients with TD could suggest that pre-TD patients have greater impairment in neuropsychological measures as well as smaller volumes of brain regions. It is of note, that the aforementioned studies have been largely conducted in patients who manifest TD relative to those without the disorder or normal controls.

To define the pathophysiologic mechanisms underlying the predisposition to a movement disorder such as TD, the identification of the "functional neuroanatomy" represented by the examination of regional cerebral glucose metabolic activity relationships may be helpful. A similar approach has been used in other illnesses such as Gilles de la Tourette's Syndrome to try to determine the "functional neuroanatomy" of patients who currently manifest the disorder (Braun et al. 1993). However, in order to examine the predisposition to TD, patients need to be studied on a long-term basis. Initially, one would need to follow patients before the development of TD in order to document its evolution. Moreover, there is no report using prospectively obtained brain measures-functional, structural, and cognitive relationships, i.e., metabolic PET scans with concomitant neuroanatomic and neurobehavioral data, in an integrated effort to determine the association to vulnerability to TD development.

We have reported a PET metabolic study on 42 patients off neuroleptics without TD (Gur et al. 1995). Patients were assessed longitudinally, and TD has emerged in eight of them during a 3-year follow-up period. Here the pattern of cerebral metabolism at intake in these patients who subsequent to the PET study developed TD is described together with neuropsychological and MRI volumetric measures and is compared with a matched sample of subjects who do not yet manifest TD.

\section{METHODS}

\section{Subjects}

Participants were recruited and assessed by the Mental Health Clinical Research Center (MHCRC) using a
Table 1. Patient Characteristics ${ }^{a}$

\begin{tabular}{lcrlcc}
\hline Matched Prs & Sex & Age & Diag & Washout & Durat \\
\hline 1 TD & M & 38 & CHR SCZ & 6 WKS & 15 YRS \\
WITHOUT TD & M & 42 & CHR SCZ & 4 & 19 \\
2 TD & M & 34 & CHR SCZ & 4 & 12 \\
WITHOUT TD & M & 38 & CHR SCZ & 114 & 14 \\
3 TD & M & 39 & CHR SCZ & 2 & 6 \\
WITHOUT TD & M & 34 & CHR SCZ & 2 & 15 \\
4D & F & 46 & CHR SCZ & 52 & 19 \\
WITHOUT TD & F & 34 & CHR SCZ & 24 & 14 \\
5 TD & M & 29 & FIR-EPI & NA & 1 \\
WITHOUT TD & M & 25 & FIR-EPI & NA & 1 \\
6 TD & M & 26 & CHR SCZ & 104 & 8 \\
WITHOUT TD & M & 26 & CHR SCZ & 260 & 15 \\
7 TD & M & 24 & FIR-EPI & NA & 7 \\
WITHOUT TD & M & 29 & FIR-EPI & NA & 10 \\
8 TD & M & 30 & FIR-EPI & NA & 8 \\
WITHOUT TD & M & 36 & FIR-EPI & NA & 7 \\
\hline
\end{tabular}

${ }^{a} \mathrm{PRS}=$ pairs; $\mathrm{TD}=$ tardive dyskinesia; $\mathrm{Diag}=$ diagnosis; $w \mathrm{ks}=$ weeks; NA = not applicable; Durat = duration; FIR-EPI = first episode; CHR SCZ $=$ chronic schizophrenia.

comprehensive medical, neurologic, and psychiatric evaluation (Gur et al. 1994). Patients met DSM-III-R criteria for schizophrenia (APA 1987) and had no history of other disorders including any movement disorder. Of 42 patients who participated in the PET study and were followed longitudinally, eight developed TD and were matched demographically and clinically (Table 1) to eight who did not yet develop symptoms of TD. The six first-episode patients had diagnoses of schizophrenia confirmed during the 3-year follow-up.

The two groups of patients, those who later developed TD and will be referred to as pre-TD (PTD) and the group that thus far shows no signs of TD and will be referred to as not yet-TD (NYTD), were matched by sex (seven men, one woman), age \pm SD at study entry (PTD $33.3 \pm 7.4 ;$ NYTD $33.0 \pm 5.9$ years), duration of illness (PTD $9.3 \pm 5.8$; NYTD $11.9 \pm 5.7$ years), medication washout for the previously treated patients (PTD $33.6 \pm$ 44.5; NYTD $80.8 \pm 110.16$ weeks), education (PTD $12.4 \pm$ 2.2; NYTD $11.9 \pm 3.4$ years), parental education level (PTD $13.0 \pm 2.3$; NYTD $12.9 \pm 2.4$ ), stage of illness (three first-episode, five previously treated). No patients were treated with clozapine during the study. In-

Figure 1. Placement of regions of interest (ROIs). Regions are marked using the following abbreviations: $\mathrm{SF}=\mathrm{superior}$ frontal; $\mathrm{DL}=$ dorsal prefrontal - lateral; $\mathrm{DM}=$ dorsal prefrontal - medial; $\mathrm{MF}=$ medial frontal; $\mathrm{IF}=$ inferior frontal; $\mathrm{SM}=$ sensorimotor; $\mathrm{PC}=$ paracentral; $\mathrm{SP}=$ superior parietal; $\mathrm{SG}=$ supramarginal gyrus; $\mathrm{OM}=$ occipital cortex - medial; $\mathrm{OL}=$ occipital cortex - lateral; LI = lingual gyrus; FG = fusiform gyrus; OT = occipital temporal; ST = superior temporal; $\mathrm{MT}=$ midtemporal; IT = inferior temporal; $\mathrm{TP}=$ temporal pole; $\mathrm{PH}=$ parahippocampal gyrus; $\mathrm{HI}=$ hippocampus; $\mathrm{PP}=$ prepiriform [uncus]; $\mathrm{AM}=$ amygdala; $\mathrm{IN}=$ insula; $\mathrm{OF}=$ orbital frontal; $\mathrm{RG}=$ rectal gyrus; $\mathrm{CA}=$ cingulate gyrus - anterior; $\mathrm{CG}=$ cingulate gyrus; $\mathrm{CP}=$ cingulate gyrus - posterior; $\mathrm{C} 1=$ corpus callosum - anterior; $\mathrm{C} 2=$ corpus callosum - posterior; $\mathrm{CN}=$ caudate nucleus; $\mathrm{LM}=$ lenticular - medial [globus pallidus]; $\mathrm{LL}=$ lenticular - lateral [Putamen]; $\mathrm{MB}=$ mammillary body; $\mathrm{TH}=$ thalamus; $\mathrm{MI}=$ midbrain; $\mathrm{PO}=$ pons; $\mathrm{CE}=$ cerebellum; 


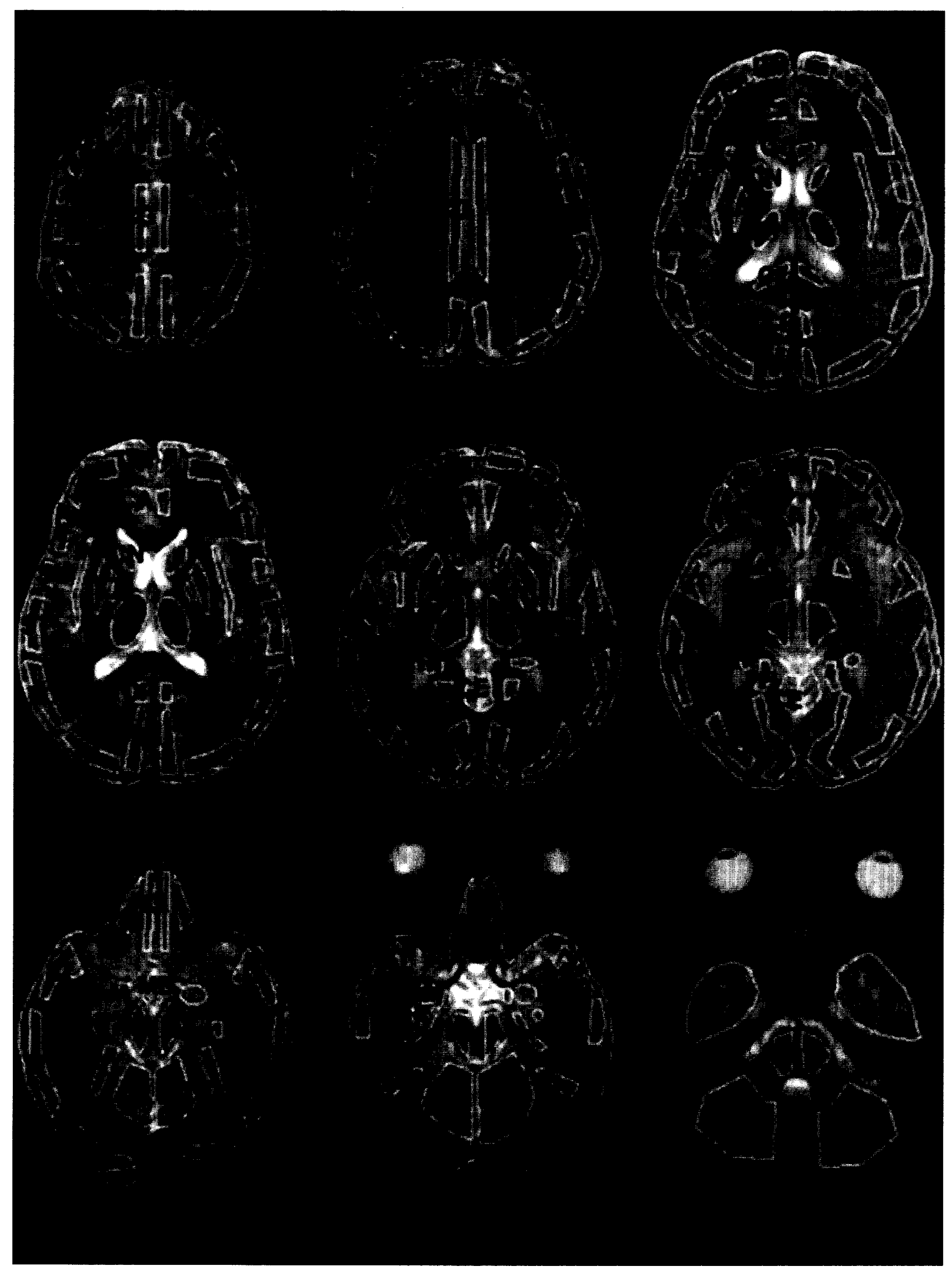


formed consent was obtained before participation in the study. All procedures were administered within 1 week of study entry.

\section{Clinical Assessment}

The following scales were completed at study entry according to procedures previously detailed (Gur et al. 1994): The Brief Psychiatric Rating Scale (BPRS) (Overall and Gorham 1962), the Scale for Assessment of Negative Symptoms (SANS) (Andreasen 1984a), the Scale for Assessment of Positive Symptoms (SAPS) (Andreasen 1984b) and the Abnormal Inventory Movements Scale (AIMS) (Simpson et al. 1979). Patients were followed with repeated structured assessment of symptoms and level of functioning at 6-month intervals for up to 3 years. The mean BPRS ratings for the PTD vs NYTD group were $47.5 \pm 6.6$ (range 37-55) and $47.1 \pm 7.4$ (range 37-55), the mean SANS global ratings were $2.8 \pm$ 0.9 and $2.5 \pm 0.8$, and for SAPS they were $2.5 \pm 0.8$ and $2.4 \pm 0.8$. None of the clinical ratings differed significantly between the two groups. The AIMS ratings were reviewed by one investigator (REG) who made a final determination based on the research diagnostic-TD criteria (Schooler and Kane 1982) as to whether the patient had a "case" of definite TD, which required at least one rating of a global 3 persisting for 3 months. TD did not emerge in patients who recently stopped medications but only became evident within the 3-year period after entering the protocol.

\section{PET Procedures}

These procedures were previously detailed (RC Gur et al. 1995; RE Gur et al. 1995). Briefly, about 185 MBQ (5 $\mathrm{mCi}$ ) of ${ }^{18} \mathrm{~F}$-labeled 2-fluoro-2-deoxy-D-glucose (FDG) was administered intravenously while the subjects lay recombinant in a quiet, dimly lit room with their eyes open and ears unoccluded. Arterial samples were obtained over the next 90 minutes.

Image aquisition began 40 minutes later with a PENN-PET scanner (Karp et al. 1990). The spatial resolution averaged $5.5 \mathrm{~mm}$ FWHM in all directions near the center of the field (Karp et al. 1991). Local cerebral metabolic rate for glucose was calculated (Reivich et al. 1979) using experimentally determined values of the

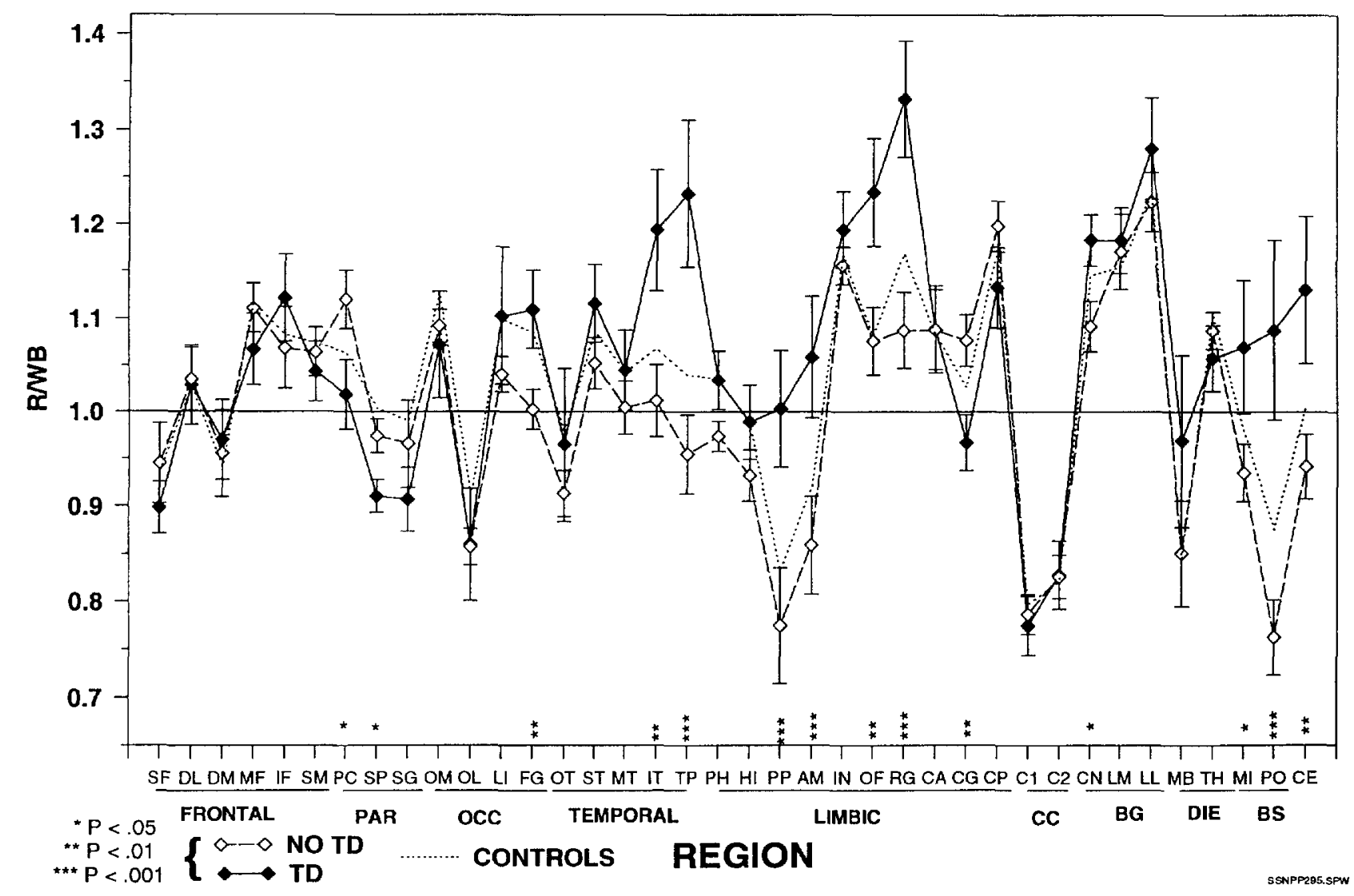

Figure 2. Topography of metabolic activity for region/whole brain means in patients with subsequent TD (full diamonds) and with no evidence for subsequent TD (empty diamonds) and normative sample (dashed line). Region abbreviations as in Figure 1; for the larger region groups abbreviations are: $\mathrm{PAR}=$ parietal, $\mathrm{OCC}=$ occipital, $\mathrm{CC}=$ corpus callosum, $\mathrm{BG}=\mathrm{basal}$ ganglia, $\mathrm{DIE}=$ diencephalon, $\mathrm{BS}=$ brainstem. 
lumped constant and rate constants (Reivich et al. 1985). Count rates were calculated as a product of the counts per pixel (cpp) means divided by the duration of the scan. The images were then exported into a SUN graphics workstation for processing along with the corresponding MRI of each subject. A set of templates with 42 regions of interest (ROIs) per hemisphere was custom fitted to each MRI slice by operators blind to diagnosis as previously detailed (Resnick et al. 1993). There were 36 ROIs where interrater reliability criterion $>0.85$ (intraclass correlation) was achieved. These regions are illustrated in Figure 1.

\section{Neuropsychological Assessment}

Patients received a comprehensive assessment battery that enabled examination of major neurobehavioral domains including: attention, abstraction-flexibility, verbal intellectual, spatial intellectual, verbal memory, spatial memory, sensory, and motor functions. The data from that battery have been published for the larger sample (Saykin et al. 1991, 1994; Kareken et al. 1995), and here we compare the profile of PTD and NYTD groups.

\section{MRI Measures}

Image acquisition, processing, and reliability procedures have been detailed elsewhere (Gur et al. 1991, 1994; Cowell et al. 1994; Turetsky et al. 1995). Briefly, MRIs were acquired on a GE Signa 1.5 Tesla scanner (Milwaukee, WI). Transaxial images were obtained in planes parallel to the orbitomeatal line. Each slice was 5 $\mathrm{mm}$ thick, and there were no interslice gaps. A multiecho acquisition sequence was used, TR $=3000$, TE $=$ 30 , and 80 mseconds. This protocol allowed measurement of the two independent properties of proton density and $T_{2}$-weighted value.

For volumetric analysis, a segmentation algorithm was established and reliability and validity was applied (Kohn et al. 1991). Proton densities and $T_{2}$-weighted values of each pixel within an operator-defined ROI were isolated from each other. Volumetric calculations were performed for global measures of brain, ventricular, and sulcal CSF, as well as for regional measures of the frontal and temporal lobes. These were calculated in milliliters for each hemisphere. Before regional measurement, brains were realigned in three dimensions and resliced along the AC-PC axis to standardize for differences in head tilt during image acquisition (Cowell et al. 1994; Turetsky et al. 1995). Resliced images were then imported into the computer software package (Kohn et al. 1991) modified to accomodate regional analysis. The borders of the frontal and temporal lobes were established by the investigators working with a neuroradiologist using standardized boundaries with interreliabilities and intrareliabilities (intraclass correlations) greater than 0.85 (Cowell et al. 1994; Turetsky et al. 1995).

\section{Data Analysis}

Absolute metabolic rates and region/whole-brain ( $R /$ WB) ratios were calculated for the 38 ROIs. Whole-brain values used for calculating $R / W B$ were based on the global values for the entire brain and thus included regions not sampled by the ROIs. Analyses were performed on both the raw metabolic rates and the R/WB ratios, which showed no differences in the main findings. Thus, as is customary, regional specificity of effects will be presented for the R/WB ratios. To establish differential topography of activity between PTD and NYTD patients, the 38 regions were subdivided into 10 areas (RC Gur et al., 1995): frontal (SF, DL, DM, MF, IF, $\mathrm{SM})$, parietal (PC, SP, SG), occipital (OM, OL, LI, GF), temporal (OT, ST, MT, IT, TP), "old" limbic (PH, HI, PP, AM, IN, OF, RG), "new" limbic: (CA, CG, CP), corpus callosum $(\mathrm{C} 1, \mathrm{C} 2)$, basal ganglia $(\mathrm{CN}, \mathrm{LM}, \mathrm{LL})$, diencephalon (MB, TH), and basal brain (MI, PO, CE). To examine whether there was a regional specific difference between the groups, a group (PTD, NYTD) $\times$ area repeated-measures ANOVA was performed, with the 10 superordinate areas serving as a within-subjects factor. A significant group $\times$ area interaction legitimized a series of group $\times$ region repeated-measures ANOVA on each area, and significant effects or interactions were followed by $t$-tests. Greenhouse-Geisser corrected $p$-values were used for the ANOVAs, and $p$ values for the $t$-tests were corrected for the number of regions within each area by using a modified Bonferroni method (Hockberg and Benjamini 1990).

The corollary analyses examined whether the two groups differed on any of the clinical, neuropsychological, and MRI measures. The clinical rating scale data were analyzed in a standard fashion yielding summary scores. The neuropsychological test data likewise provide standardized scores for eight major dimensions: attention, abstraction-flexibility, verbal intellectual, spatial intellectual, verbal memory, spatial memory, sensory, and motor (Kareken et al. 1995). MRI volumetric measures included whole brain, ventricular CSF, sulcal CSF, frontal lobe, and temporal lobe for each hemisphere. The two groups were compared on these scores by $t$-tests.

\section{RESULTS}

Global whole brain metabolism did not differ between the two groups (PTD $4.8 \pm 1.0$, NYTD $4.4 \pm 1.5$ ), $\mathrm{t}(14)<$ 1. The group $\times$ area ANOVA for the raw values 
showed no main effect for group, $(\mathrm{F}=1.32, d f=1,14$, $p=.26)$, but a significant group $\times$ area interaction $(\mathrm{F}=$ $7.51, d f=9,126, p=.001$ ) indicated higher values for the PTD than for the NYTD group in specific regions. Therefore, the main regional analyses were performed on the $\mathrm{R} / \mathrm{WB}$ ratios. These values for the two groups of subjects in 38 regions are presented in Figure 2, along with the means for the normative comparison sample of 42 healthy subjects (mean age $28.5 \pm 7.2$ years). The ANOVA on the R/WB ratios for the frontal regions showed neither a group main effect nor a group $\times$ region interaction. The ANOVA on the parietal regions showed a main effect of group, $(F=8.11, d f=1,14, p=$ $.014)$, with lower relative values in the PTD group. The ANOVA for the occipital regions showed no main effect or interaction. The ANOVA for the temporal regions showed marginal main effect of group, $(\mathrm{F}=4.06$, $d f=1,14, p=.063$ ), with PTD patients having higher relative metabolism, and a group $\times$ region interaction, $(\mathrm{F}=5.90, d f=4,56, p=.003)$. As can be seen in Figure 2, the interaction reflects the specificity of this effect for the inferior temporal and temporal pole regions. The ANOVA for the old limbic region showed a main effect of group ( $\mathrm{F}=9.32, d f=1,14, p=.008)$, the PTD patients with higher values, and a group $\times$ region interaction $(\mathrm{F}=3.07, d f=6,84, p=.035)$, indicating the specificity of this effect for the prepiriform (uncus), amygdala, orbitofrontal region, and rental gyrus. ANOVA for the cingulate gyrus (new limbic) revealed a main effect of group $(\mathrm{F}=6.67, d f=1,14, p=.021)$, with PTD patients having relatively lower metabolism. ANOVAs for the corpus callosum, basal ganglia, and the diencephalic regions showed no significant group effects or interactions. However, the caudate nucleus does show a difference with higher metabolic values in patients who developed $\operatorname{TD}(t=2.37, d f=14, p=.033)$. The ANOVA on the basal brain regions showed a main effect of group ( $\mathrm{F}=7.50, d f=1,14, p=.016$ ), PTD patients with higher values, and a group $\times$ region interaction $(\mathrm{F}=$ $4.04, d f=2,28, p=.049$ ). The interaction reflected the larger difference between the groups for cerebellum and pons relative to the midbrain region (Figure 2).

The neuropsychological measures and the MRI values are presented in Tables 2 and 3 respectively. The PTD group had poorer performance on some neuropsychological measures and higher CSF volumes on the MRI. However, none of the differences between the PTD and NYTD groups is significant at study entry when correcting the $p$ value for number of comparisons.

\section{DISCUSSION}

Vulnerability to the development of TD in patients with schizophrenia was associated with a specific pattern of cerebral metabolic activity. Against a background of
Table 2. Neuropsychological Performance for PTD and NYTD Patients

\begin{tabular}{|c|c|c|c|c|}
\hline & \multicolumn{2}{|c|}{ PTD } & \multicolumn{2}{|c|}{ NYTD } \\
\hline & Mean & SD & Mean & SD \\
\hline \multicolumn{5}{|l|}{ Executive } \\
\hline \multicolumn{5}{|l|}{ WCST } \\
\hline \# Categories & 3.00 & 2.39 & 4.88 & 3.23 \\
\hline \%persev & 0.35 & 0.30 & 0.18 & 0.09 \\
\hline \multicolumn{5}{|l|}{ Attention } \\
\hline CPT & 22.71 & 10.47 & 26.50 & 5.24 \\
\hline DSP & 7.88 & 3.44 & 8.87 & 2.30 \\
\hline TRA & 53.63 & 38.37 & 40.86 & 23.97 \\
\hline TRB & 151.63 & 80.82 & 149.71 & 105.27 \\
\hline \multicolumn{5}{|l|}{ Memory: Verbal } \\
\hline WMS-IM & 8.07 & 5.05 & 14.12 & 8.27 \\
\hline WMS-DEL & 7.36 & 5.88 & 11.12 & 9.57 \\
\hline CVLT & 32.50 & 13.34 & 40.00 & 17.39 \\
\hline \multicolumn{5}{|l|}{ Memory: Spatial } \\
\hline WMS-IM & 6.50 & 4.63 & 7.25 & 4.65 \\
\hline WMS-DEL & 6.00 & 4.75 & 5.50 & 4.96 \\
\hline \multicolumn{5}{|l|}{ Language } \\
\hline CFL & 21.25 & 14.14 & 29.37 & 8.14 \\
\hline $\mathrm{AN}$ & 14.00 & 6.46 & 19.33 & 3.78 \\
\hline BNT & 47.12 & 7.26 & 47.37 & 10.78 \\
\hline TOKEN & 36.80 & 5.76 & 35.83 & 9.04 \\
\hline READ & 95.57 & 21.67 & 79.50 & 14.92 \\
\hline \multicolumn{5}{|l|}{ Spatial } \\
\hline BLOT & 23.00 & 2.00 & 19.33 & 10.86 \\
\hline $\mathrm{BD}$ & 8.25 & 1.58 & 8.00 & 3.96 \\
\hline \multicolumn{5}{|l|}{ Sensory } \\
\hline \multicolumn{5}{|l|}{ Right } \\
\hline TAC & 0.37 & 1.06 & 2.28 & 3.59 \\
\hline AUD & 0.13 & 0.35 & 0.57 & 0.53 \\
\hline VIS & 0.43 & 0.79 & 0.71 & 1.89 \\
\hline GR & 5.13 & 5.16 & 4.26 & 4.50 \\
\hline \multicolumn{5}{|l|}{ Left } \\
\hline $\mathrm{TAC}$ & 0.75 & 0.70 & 1.29 & 1.98 \\
\hline AUD & 0.50 & 1.07 & 0.29 & 0.75 \\
\hline VIS & 0.14 & 0.37 & 1.14 & 2.61 \\
\hline GR & 4.38 & 5.65 & 3.50 & 3.07 \\
\hline \multicolumn{5}{|l|}{ Motor } \\
\hline \multicolumn{5}{|l|}{ Right } \\
\hline TAP & 43.16 & 13.21 & 44.42 & 6.71 \\
\hline $\mathrm{FT}$ & 8.57 & 2.57 & 7.57 & 1.90 \\
\hline \multicolumn{5}{|l|}{ Left } \\
\hline TAP & 41.87 & 11.84 & 41.45 & 10.31 \\
\hline $\mathrm{FT}$ & 7.71 & 2.63 & 7.57 & 1.72 \\
\hline
\end{tabular}

Note: WCST $=$ Wisconsin card sorting test CPT $=$ continous performance test; $\mathrm{DSP}=$ digit span $($ WAIS-R): $\mathrm{TRA}=$ trails $-\mathrm{A} ; \mathrm{TRB}=$ trail $=$ $\mathrm{B} ; \mathrm{WMS}=$ Wechsler memory scale; $\mathrm{CVLT}=$ California verbal learning test; $\mathrm{CFL}=$ Benton's verbal fluency test; $\mathrm{AN}=$ animal naming; $\mathrm{BNT}=$ Boston naming test; TOKEN $=$ Benton's token test; READ = WRAT reading test; $\mathrm{BLOT}=$ Boston line operation test; $\mathrm{BD}=$ block design (WAIS-R): TAC = tactile sensory examination (Halstead-Reitan batery); AUD $=$ auditory sensory examination $(\mathrm{HRB})$; VIS = visual sensory examination (HRB); GR = graphesthesia (HRB); TAP = finger tapping $(\mathrm{HRB}) ; \mathrm{FT}=$ fingertip number writing $(\mathrm{HRB})$. 
Table 3. MRI Volumetric Measures for PTD and NYTD Patients

\begin{tabular}{lrrrrr}
\hline & \multicolumn{2}{c}{ PTD } & & \multicolumn{2}{c}{ NYTD } \\
\cline { 2 - 3 } \cline { 6 - 6 } & Mean & SD & & Mean & SD \\
\hline Whole Brain & 1135.42 & 147.46 & & 1001.48 & 180.32 \\
CSF & & & & & \\
$\quad$ Ventricles & 21.02 & 12.79 & & 17.15 & 8.18 \\
$\quad$ Sulci & 105.03 & 40.69 & & 81.70 & 58.81 \\
Frontal Lobes & & & & & \\
$\quad$ Tissue & 215.42 & 38.99 & & 194.28 & 29.95 \\
$\quad$ CSF & 24.72 & 9.53 & & 14.52 & 9.86 \\
Temporal Lobe & & & & \\
$\quad$ Tissue & 222.54 & 39.47 & & 214.01 & 26.10 \\
$\quad$ CSF & 15.94 & 6.44 & 11.06 & 4.10 \\
\hline
\end{tabular}

nearly identical distribution of activity in most other brain regions, patients who developed TD had hypermetabolism of the temporolimbic, brainstem, and cerebellar regions, and hypometabolism in parietal and cingulate regions. Thus, metabolic abnormalities in functionally related cortical and subcortical regions predate the development of TD and can be related to increased vulnerability to the disorder. Furthermore, the more pronounced differences between the groups were in the direction of hyperactivity. Hypermetabolism indicated that greater neuronal activity in specific brain regions was related to an increased risk of TD development.

One model of TD proposes a structural lesion, which would likely show basal ganglia hypometabolism on PET FDG measures. In a recent primate experiment where a destructive neuronal lesion in the basal ganglia was induced, reduced PET FDG metabolism was seen (Brownell et al. 1994). Our findings do not fit this possible model of TD, because the subsequent development of this disorder was associated with increased metabolism in most regions. Perhaps TD evolves from an initial hypermetabolic state in certain brain regions to a later structural lesion in an area such as the basal ganglia where hypometabolism would be seen. Whether this occurs could be established by repeated scans of patients over time before and after their development of TD.

Because movement disorders in schizophrenia have been associated with cognitive deficits (Waddington et al. 1987, 1993), it is noteworthy that the two groups did not differ at a statistically significant level in their neuropsychological performance at the time of PET study. The PTD group only showed a trend toward poorer performance. Identical levels of neuropsychological functioning were found for the motor items. Likewise, no statistically significant differences were noted for the neuroanatomic measures in the regions examined. However, subcortical regions implicated in the pathophysiology of TD were not evaluated in the current study.
There are several limitations to this study. The sample was small, as only eight patients have developed TD by the 3-year follow-up. Our strategy was to match as closely as possible this group of patients to a group that did not develop TD during this period. Matching was not entirely accurate on past neuroleptic history, because we do not have complete data on patients before their enrollment in the study. However, because the patients were matched by age, duration, and stage of illness, it is unlikely such a difference could explain the results. General clinical history was also considered in the matching and the level of positive and negative symptomatology at the time of the PET study was comparable.

These findings may enhance the general understanding of the pathophysiologic mechanisms leading to the clinically detrimental complication of tardive dyskinesia. Because cerebral PET FDG measures may indicate general synaptic activity, changes in metabolism may suggest altered functional relationships in certain brain regions. Future research should be directed at examining cerebral PET FDG measures in subjects with existing TD. This study underscores the need for a longitudinal design in efforts to both understand and eventually control the development of this disabling medication effect in schizophrenia.

\section{ACKNOWLEDGMENTS}

This research was performed at the University of Pennsylvania and supported by the National Institute of Health Grants MH-43880, MH-00586, MH-48539, NS-14867, MH-42191, MO1RR0040 and by the EJLB Foundation. We thank D. Sandefur, K. Hambrose Martin, MSN, RN, T. Thew BS, and H. Mitchell-Sears, BA for assistance and the staff of the PET Center for performing the scans.

\section{REFERENCES}

Albus M, Naber D, Muller-Spahn F, Douillet P, Reinertshofer T, Achenheil M (1985): Tardive dyskinesia: Relation to computer-tomographic, endocrine, and psychopathological variables. Biol Psychiatry 20(10):1082-1089

American Psychiatric Association DSM-III-R (1987): Diagnostic and Statistical Manual of Mental Disorders, 3rd edition revised. Washington, DC: American Psychiatric Press

Andersson U, Erkernas SA, Hartvig P, Ulin J, Langston B, Haggstrom JE (1990): Striatal binding of 11C-NMSP studied with positron emission tomography in patients with tardive dyskinesia: No evidence for altered dopamine $\mathrm{D}_{2}$ receptor binding. J Neural Trans Gen Section 79:215-216

Andreasen NC (1984a): The Scale for the Assessment of Negative Symptoms (SANS). Iowa City, IA: The University of Iowa. 
Andreasen NC (1984b): The Scale for the Assessment of Positive Symptoms (SAPS). Iowa City, IA: the University of Iowa.

Blin J, Baron JC, Cambon H, Bonnet AM, Dubois B, Loc'h C, Mazeire B, Agid Y (1989): Striatal dopamine $D_{2}$ receptors in tardive dyskinesia: PET study. J Neurol Neurosurg Psychiatry 52:1248-1252.

Braun AR, Stoetter B, Randolph C, Hsiao JK, Vladar K, Gernert J, Carson RE, Herscovitch P, Chase T (1993): The functional neuroanatomy of Tourette's Syndrome: An FDG-PET study. I. Regional changes in cerebral glucose metabolism differentiating patients and controls. Neuropsychopharmacology 9:277-291

Brownell AL, Hantraye P, Wullner U, Hamberg L, Shoup T, Elmaleh DR, Firm DM, Madras BK, Brownell GL, Rosen BR (1994): PET- and MRI-based assessment of glucose utilization, dopamine receptor binding and hemodynamic changes after lesions to the caudate-putamen in primates. Exp Neurol 125:41-51

Casey DE (1993): Neuroleptic-induced acute extrapyramidal syndromes and tardive dyskinesia. Psychopharmacology 16:589-610

Cohen H, Cohen D (1993): What may be gained from neuropsychological investigations of tardive dyskinesia? Brain Cogn 23:1-7

Cowell PE, Turetsky BT, Gur RC, Grossman RI, Shtasel DL, Gur RE (1994): Sex differences in aging of the human frontal and temporal lobe. J Neurosci 14:4748-4755

Dalgalarrondo P, Gattaz WF (1994): Basal ganglia abnormalities in tardive dyskinesia. Possible relationship with duration of neuroleptic treatment. Eur Arch Psychaitry Clin Neurosci 244(5):272-277

Elkashef AM, Buchanan RW, Gellad F, Munson RC, Breier A (1994): Basal ganglia pathology in schizophrenia and tardive dyskinesia: An MRI quantitative study. Am J Psychiatry 151(5):752-755

Gold JM, Egan MF, Kirch DG, Goldberg TE, Daniel DG, Bigelow LB, Wyatt RJ (1991): Tardive dyskinesia: Neuropsychological, computerized tomographic, and psychiatric symptom findings. Biol Psychiatry 30(6):587-599

Gur RC, Mozley PD, Resnick SM, Karp JS, Alavi A, Arnold $\mathrm{SE}$, Gur RE (1995): Sex differences in regional cerebral glucose metabolism during a resting state. Science 267:528-531

Gur RE, Mozley PD, Resnick SM, Shtasel D, Kohn M, Zimmerman R, Herman G, Atlas S, Grossman R, Erwin R, Gur RC (1991): Magnetic resonance imaging in schizophrenia I. Volumetric analysis of brain and cerebrospinal fluid. Arch Gen Psychiatry 48:407-412

Gur RE, Mozley PD, Shastel DL, Cannon TD, Gallacher D, Turetsky B, Grossman R, Gur RC (1994): Clinical subtypes of schizophrenia differ in brain and cerebrospinal fluid volume. Am J Psychiatry 151:343-350

Gur RE, Mozley PD, Resnick SM, Harper-Mozley L, Shastel DL, Gallacher F, Arnold SE, Karp JS, Alavi A, Reivich M, Gur RC, (1995): Resting cerebral glucose in first-episode and previously treated patients with schizophrenia relates to clinical features. Arch Gen Psychiatry 52:657667

Heinz R, Rayasam K, Krishnan KR, Wingfield M, Irigaray P,
Ellinwood EH (1988): MRI scans in patients with tardive dyskinesia. Biol Psychiatry 24(7):852-857

Hockberg Y, Benjamini Y (1990): More powerful procedures for multiple significance testing. Stat Med 9:811-818

Hoffman WF, Casey DE (1991): Computed tomographic evaluation of patients with tardive dyskinesia. Schizophr Res 5:1-12

Kareken DA, Gur RC, Mozley PD, Mozley LH, Saykin AJ, Shtasel DL, Gur RE (1995): Cognitive functioning and neuroanatomic volume measures in schizophrenia. Neuropsychology 9:211-219

Karp JS, Muehllehner G, Mankoff DA, Ordonez CE, Ollonger JM, Daube-Witherspoon ME, Haigh AT, Beerbohm DJ (1990): Continuous slice PENN-PET: A positron tomograph with volume imaging capability. J Nucl Med 5:517-527

Karp JS, Daube-Witherspoon ME, Muehllehner G (1991): Factors affecting accuracy and precision in PET volume imaging. J Cereb Blood Flow Metab 14:A38-A44

Kohn MI, Tanna NK, Herman GT, Resnick SM, Mozley PD, Gur RE, Alavi A, Zimmerman RA, Gur RC (1991): Analysis of brain and CSF volumes from magnetic resonance imaging: methodology, reliability and validation. Radiology 178:115-122

Mion CC, Andreasen NC, Arndt S, Swayze VW, Cohen C (1991): MRI abnormalities in tardive dyskinesia. Psychiatry Res 40(3):157-166

Overall JR, Gorham DR (1962): The brief psychiatric rating scale. Psychol Rep 10:799-812

Reivich M, Kuhl D, Wolf AP, Greenberg J, Phelps M, Ido T, Casella V, Fowler J, Hoffman E, Alavi A, Som P, Sokoloff L (1979): The 18 F-fluorodeoxyglucose method for the measurement of local cerebral glucose utilization in man. Circ Res 44:127-137

Reivich M, Alavi A, Wolf AP, Fowler JS, Russell J, Arnett C, MacGregor RR, Shive CY, Atkins H, Anand A, Dann R, Greenberg JH (1985): Glucose metabolic rate kinetic model parameter determination in man. The lumped constants and rate constants for $18 \mathrm{~F}$-Fluorodeoxyglucose and 11C-Deoxyglucose. J Cereb Blood Flow Metab 5:179-192

Resnick SM, Karp JS, Turetsky B, Gur RE (1993): Comparison of anatomically-defined versus physiologically-based regional localization: Effects on PET-FDG quantiifcation. J Nucl Med 34:2201-2207

Saykin AJ, Gur RC, Gur RE, Mozley D, Mozley LH, Resnick SM, Kester DB, Stafiniak P (1991): Neuropsychological function in schizophrenia: Selective impairment in memory and learning. Arch Gen Psychiatry 48:618-624

Saykin AJ, Shtasel DL, Gur RE, Kester DB, Mozley LH, Stafiniak P, Gur RC (1994): Neuropsychological deficits in neuroleptic naive, first episode schizophrenic patients. Arch Gen Psychiatry 51:124-131

Schooler N, Kane J (1982): Research diagnoses for tardive dyskinesia. Arch Gen Psychiatry 391:486-487

Simpson GM, Lee JH, Zoubek B, Gardos G (1979): A rating scale for tardive dyskinesia. Psychopharmacology 64: 171-179

Turetsky BT, Cowell PE, Gur RC, Grossman RI, Shtasel DL, 
Gur RE (1995): Frontal and temporal lobe brain volumes in schizophrenia: Relationship to symptomotology and clinical subtype. Arch Gen Psychiatry, in press.

Waddington JL, Youssef HA, Dolphin C, Kinsell A (1987): Cognitive dysfunction, negative symptoms and tardive dyskinesia in schizophrenia: Their association in rela- tion to topography of involuntary movements and criterion of their abnormality. Arch Gen Psychiatry 44: 907-912

Waddington JL (1993): Cognitive dysfunction in schizophrenia: Organic vulnerability factor or state marker for tardive dyskinesia? Brain Cogn 23:56-70 